\title{
In vitro and in vivo trematode models for chemotherapeutic studies
}

\author{
J. KEISER* \\ Department of Medical Parasitology and Infection Biology, Swiss Tropical Institute, CH-4002 Basel, Switzerland
}

(Received 27 June 2009; revised 7 August 2009 and 26 October 2009; accepted 27 October 2009; first published online 7 December 2009)

\begin{abstract}
S U MMARY
Schistosomiasis and food-borne trematodiases are chronic parasitic diseases affecting millions of people mostly in the developing world. Additional drugs should be developed as only few drugs are available for treatment and drug resistance might emerge. In vitro and in vivo whole parasite screens represent essential components of the trematodicidal drug discovery cascade. This review describes the current state-of-the-art of in vitro and in vivo screening systems of the blood fluke Schistosoma mansoni, the liver fluke Fasciola hepatica and the intestinal fluke Echinostoma caproni. Examples of in vitro and in vivo evaluation of compounds for activity are presented. To boost the discovery pipeline for these diseases there is a need to develop validated, robust high-throughput in vitro systems with simple readouts.
\end{abstract}

Key words: Schistosoma mansoni, Fasciola hepatica, Echinostoma caproni, in vitro, in vivo, drug discovery, chemotherapy.

\section{INTRODUCTION}

Thus far approximately 6000 species in the sub-class Digenea, phylum Platyhelminthes have been described in the literature. Among them, only a dozen or so species parasitize humans. These include the blood flukes (five species of Schistosoma), liver flukes (Clonorchis sinensis, Fasciola gigantica, Fasciola hepatica, Opisthorchis felineus and Opisthorchis viverrini), lung flukes (Paragonimus spp.) and intestinal flukes (e.g. Echinostoma spp. and Fasciolopsis buski) (Cox, 1993; Keiser and Utzinger, 2009). These parasites are the causative agents of a complex of some acute, but mainly chronic infections: schistosomiasis and food-borne trematodiases (Keiser and Utzinger, 2007; Utzinger et al. 2007; Davis, 2009; Sithiathaworn et al. 2009). It is currently estimated that 1400 million people are at risk of schistosomiasis and food-borne trematodiases with more than 250 million infections (Keiser and Utzinger, 2005; Steinmann et al. 2006). Whilst the global burden of schistosomiasis has been estimated at $1 \cdot 7-4 \cdot 5$ million disability-adjusted life years (Utzinger and Keiser, 2004; Hotez et al. 2009), that of food-borne trematodiases remains to be investigated (Keiser and Utzinger, 2009). Schistosomiasis and food-borne trematodiases belong to the so-called neglected tropical diseases (Hotez et al. 2009; Keiser and Utzinger, 2009). The global strategy for the control of schistosomiasis and food-borne trematodiases and other parasitic worm infections is morbidity control

\footnotetext{
* Corresponding author: Tel: +4161 284-8218; Fax: +4161284-8105. E-mail: jennifer.keiser@unibas.ch
}

by chemotherapy. However, only two drugs are currently available: triclabendazole against fascioliasis and praziquantel against the other food-borne trematode infections and schistosomiasis (Keiser and Utzinger, 2004; Keiser et al. 2005). Hence, there is a need for discovery and development of new drugs, particularly in view of growing concern about resistance developing to existing drugs. Triclabendazole resistance is already common in veterinary parasitology (Keiser et al. 2005) and the extensive use of praziquantel resistance in mass drug administration programs has raised concern regarding the selection of drug resistant schistosomes (Melmann et al. 2009).

There has been little incentive to invest in the discovery and development of trematodicidal drugs. While public-private partnerships have been formed for some of the neglected tropical diseases (e.g. the Drugs for Neglected Diseases Initiative (DNDi) focusing on human African trypanosomiasis and leishmaniasis), devoted drug discovery and development programmes do not yet exist for any of the major helminth diseases (Ridley and Kita, 2007). Moreover, funding for basic research on these parasites and the pathogenesis of neglected tropical diseases has been inadequate (Renslo and McKerrow, 2006). To date, in vitro cultivation of trematodes lags behind the cultivation of protozoa or bacteria and cultivation throughout the entire life cycle is not possible (Smyth and Halton, 1983). Additionally, only very few digeneans are maintained in the laboratory, primarily due to their complex life cycles. Life cycles requiring at least 2 hosts, a vertebrate and a molluscan host, are the rule among digeneans 
(Cox, 1993; Gryseels et al. 2006; Keiser and Utzinger, 2009). Finally, though target-based trematodicidal drug discovery is starting to bear fruit (Caffrey, 2007; Sayed et al. 2008; Abdulla et al. 2009), translation of targets identified through comparative genome searches and microarray analysis into validated targets will require substantial economic efforts (Renslo and McKerrow, 2006).

In the present article, I review in vitro and in vivo trematode models available for chemotherapeutic studies. Emphasis is placed on screening against whole parasites since a molecular-target approach is still rarely employed in trematodicidal drug discovery. The focus is on a blood fluke (Schistosoma mansoni), a liver fluke (Fasciola hepatica) and an intestinal fluke (Echinostoma caproni). While S. mansoni and $F$. hepatica are major human pathogens, E. caproni is a rodent and avian fluke, which is widely and effectively used as a laboratory model. Examples of in vitro and in vivo evaluation of compounds for activity against these three selected flukes are given. I conclude that for better targeted future trematodicidal drug discovery there is a strong need to develop validated, robust high-throughput in vitro systems with simple readouts.

\section{SCHISTOSOMA MANSONI}

\section{S. mansoni is an important model to study} schistosomiasis

S. mansoni is the most widely used schistosome model, and its life cycle is kept in many institutions worldwide. Fig. 1 summarizes laboratories in Europe, USA, South America, Asia and Northern Africa, which currently maintain the life cycle of S. mansoni. Several of these laboratories such as the Schistosomiasis Resource Center (Biomedical Research Institute; Bethesda, USA) or the Theodor Bilharz Research Institute, Giza, Egypt also provide schistosome material for research or teaching purposes. Remarkably, our search did not identify any laboratories in sub-Saharan Africa (the area considered to be most severely affected by schistosomeinduced morbidity (van der Werf et al. 2003), which maintain the complete laboratory life-cycle of S. mansoni.

Briefly, in the definitive host $S$. mansoni worms develop from a post-penetration larval stage, the schistosomulum. The female worms produce eggs which leave the body in excreta - faeces in the case of S. mansoni, and on contact of the eggs with fresh water free-swimming miracidia hatch out and infect snails. For laboratory culture miracidia are hatched from $S$. mansoni eggs taken from experimental animal livers and/or intestines and Biomphalaria glabrata is the intermediate host snail species most commonly used (Fig. 2). Following asexual reproduction in the snails, cercariae are shed from the snails into freshwater (Lewis, 2001).
S. haematobium is much less studied, as it is difficult to grow in rodents (Doenhoff et al. 2009). To my knowledge, the life cycle of $S$. haematobium is currently maintained only in two laboratories, namely the Theodor Bilharz Research Institute (Giza, Egypt) and the Schistosomiasis Resource Center. 'Sibling' species of S. haematobium, such as S. bovis, S. matthei or S. margrebowiei, the life cycles of which can be maintained in laboratory rodents, might serve as models for S. haematobium (Agnew et al. 1989).

S. japonicum, the third major human schistosome species, is mainly studied in China. Nonetheless several institutions outside China maintain the life cycle and infected snails and mammals are also available on request from the Schistosomiasis Resource Center. Though less frequently used, schistosome species infecting other species of definitive hosts might also prove useful for experimental studies : for example, the bird schistosome Trichobilharzia ocellata reaches oviposition after 9 days already and is not pathogenic. Its life cycle has been described as troublesome (Smyth and Halton, 1983).

\section{S. mansoni in vitro assay based on schistosomula}

Following the establishment of the $S$. mansoni life cycle in the laboratory, in vitro parasite culture techniques were developed (Ramirez et al. 2007). Early work with schistosomula was based on the recovery of young worms from the lungs of infected rodents, hence only limited worm material was available (Smyth and Halton, 1983). The discovery that schistosomula can be obtained by transforming cercariae using simple techniques as centrifugation, repeated aspiration through a syringe needle or chemical stimulation was a breakthrough in the field of schistosome cultivation. Today cercariae are often used as starting material for schistosome in vitro studies as large numbers of schistosomula can be obtained in a cost-effective manner (Table 1, Fig. 2) (Smyth and Halton, 1983; Abdulla et al. 2009; Caffrey et al. 2009). In addition, most importantly, the use of mechanically obtained schistosomula reduces and replaces the use of live animals in accordance with the $3 \mathrm{Rs}$ (reduce, replace, refine) of animal protection principles (Broadhead and Bottrill, 1997). An assay with artificially produced schistosomula might serve as a pre-screen in drug sensitivity assays, however one has to keep in mind that mechanically transformed schistosomula possess distinct differences to schistosomula, which have penetrated the skin (e.g. biochemical differences) or juvenile and adult schistosomes (Brink et al. 1977).

Several techniques for transforming cercariae and maintaining schistosomula are available (Colley and Wikel, 1974; Howells et al. 1974; Ramalho-Pinto et al. 1974; Brink et al. 1977; Smyth and Halton, 


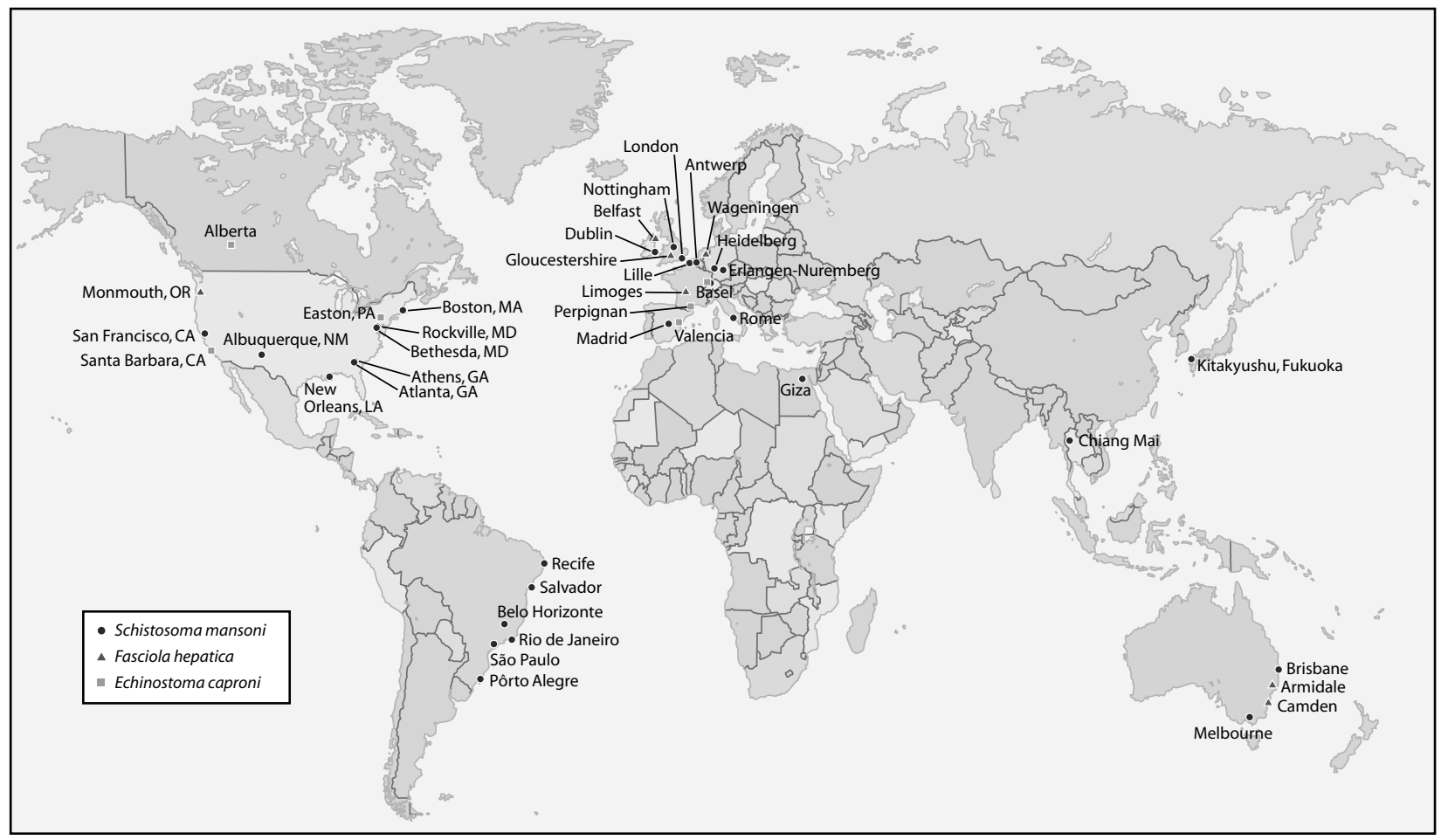

Fig. 1. World map highlighting locations of laboratories, which maintain the life cycles of S. mansoni (circles), $F$. hepatica (triangles) and E. caproni (squares). Laboratories were identified through contacting experts and literature searches (using PubMed) restricted to the past 5 years.

Schistosoma mansoni: Aggeu Magalhães Institute (FIOCRUZ) (Recife, Brazil), Biomedical Research Institute (Rockville, MD, USA), Butantã Institute, São Paulo (São Paolo, Brazil), Catholic University of Rio Grande do Sul (Porto Alegre, Brazil), CDC Atlanta (Atlanta, GA, USA), Chiang Mai University (Chiang Mai, Thailand), DBL-Centre for Health Research and Development (Copenhagen, Denmark), Federal University of Rio de Janeiro (Rio de Janeiro, Brazil), GIDE - Federal University of Minas Gerais (Belo Horizonte, Brazil), Gonçalo Muniz Institute (FIOCRUZ) (Salvador, Brazil), Institut Pasteur de Lille (Lille, France), Instituto René Rachou-Fiocruz (Belo Horizonte, Brazil), London School of Hygiene and Tropical Medicine (London, UK), Natural History Museum (London, UK), National Research Council (Rome, Italy), Oswaldo Cruz Institute (FIOCRUZ) (Rio de Janeiro, Brazil), Queensland Institute of Medical Research (Brisbane, Australia), Swiss Tropical Institute (Basel, Switzerland), Theodor Bilharz Research Institute (Giza, Egypt), Trinity College (Dublin, Ireland), Tufts University (Boston, MA, USA), Tulane University (New Orleans, LA. USA), Universidad San Pablo-CEU (Madrid, Spain), University Erlangen-Nuremberg (Erlangen-Nuremberg, Germany), University New Mexico (Albuquerque, NM, USA), University of Antwerp (Antwerp, Belgium), University of California San Francisco (San Francisco, USA), University of Georgia (Athens, GA, USA), University of Heidelberg (Heidelberg, Germany), University of Melbourne (Melbourne, Australia), University of Nottingham (Nottingham, UK), University of Occupational and Environmental Health (Kitakyushu, Fukuoka, Japan), University of São Paulo (São Paolo, Brazil), University of São Paulo, Ribeirão Preto (São Paolo, Brazil), University of Texas Health Science Center (San Antonio, TX, USA), University of the Health Sciences (Bethesda, MD, USA), University of York (York, UK). Fasciola hepatica: Baldwin Aquatics (Monmouth, OR, USA), Elizabeth Macarthur Agricultural Institute (Camden, Australia), Facultés de Médecine et de Pharmacie (Limoges, France), Queens University of Belfast (Belfast, Northern Ireland), Ridgeway Research Ltd (Gloucestershire, UK), Veterinary Health Research (Armidale, NSW, Australia), Wageningen University (Wageningen, Netherlands). Echinostoma caproni: Lafayette College (Easton, PA, USA), Swiss Tropical Institute (Basel, Switzerland), Universidad de Valencia (Valencia, Spain), Université de Perpignan (Perpignan, France), University of Alberta (Alberta, Canada), University of California Santa Barbara (Santa Barbara, CA, USA).

1983; Abdulla et al. 2009; Caffrey et al. 2009). In our laboratories, for example, a Vortex transformation method based on Ramalho-Pinto (Ramalho-Pinto et al. 1974) is used. Briefly, $50 \mathrm{ml}$ of an ice-cold cercarial suspension is centrifuged and the packed cercariae are resuspended and vortexed for $2 \mathrm{~min}$ to trigger tail loss. For the isolation of cercarial bodies from tails, an ice-cold Hank's basal salt solution (HBSS) is added to the cercarial suspension and the tail-rich supernatant is decanted (Manneck et al. 2009). Schistosomula are incubated in Basch medium (Basch, 1981) supplemented with serum and antibiotics or other culture media (Smyth and Halton, 1983). Our own studies have shown that schistosomula survive for at least $96 \mathrm{~h}$ in different media (Basch, MEM, DMEM or TC 199) regardless of serum supplementation (author's unpublished observations). Abdulla and colleagues have recently 


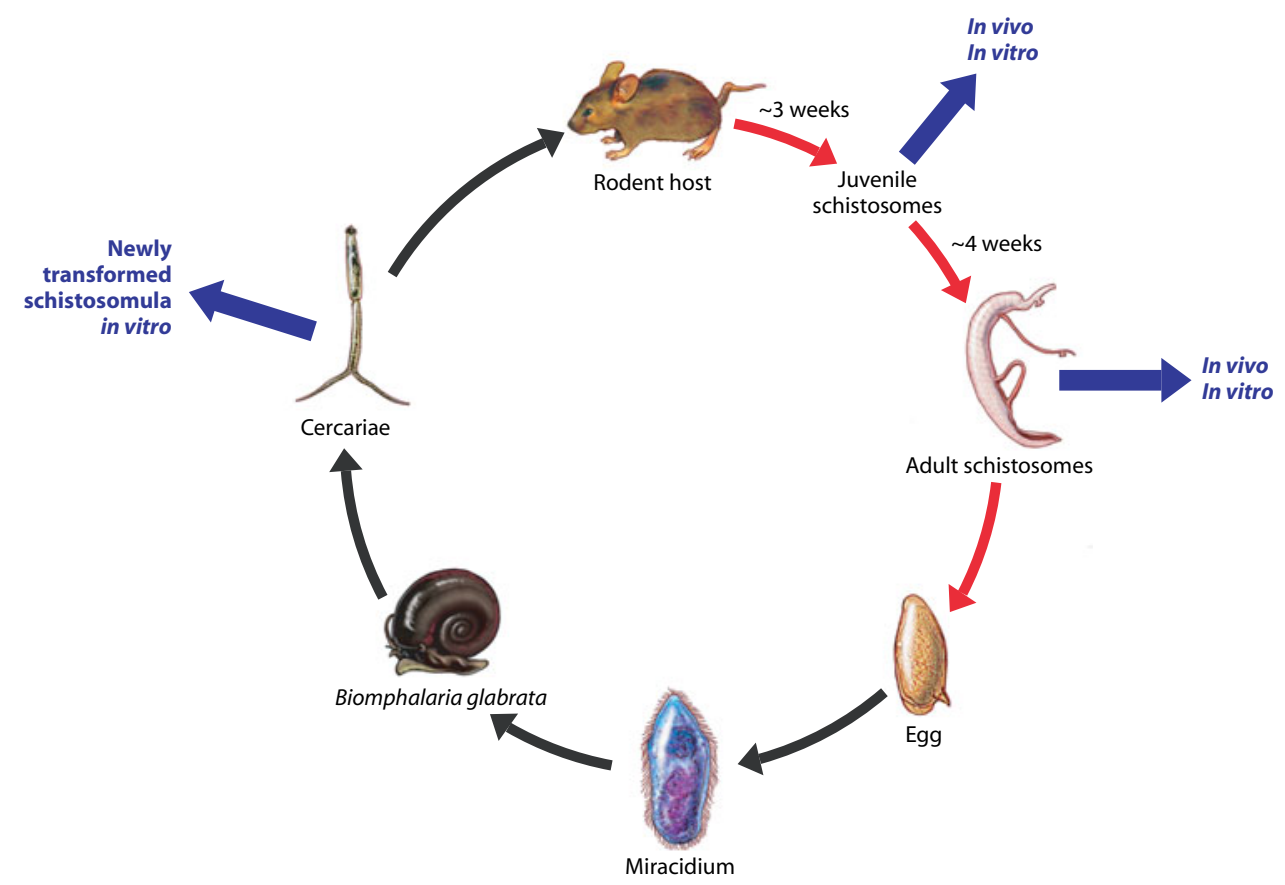

Fig. 2. Life cycle of S. mansoni highlighting collection points for in vitro and in vivo chemotherapeutic studies. Maturation of parasite occurs within final host (red arrows).

reported that schistosomula survive in Basch medium for several weeks (Abdulla et al. 2009). In Fig. 3a schistosomula incubated for $24 \mathrm{~h}$ in Basch medium are shown. Fig. $3 \mathrm{~b}$ depicts a scanning electron microscopic (SEM) image of a newly transformed schistosomulum obtained by Vortex transformation. Following incubation of schistosomula with investigational drugs, changes in worm motor activity, morphological/tegumental alterations and occurrence of death are recorded at different time points. These phenotypic changes might be scored using a viability scale from 0 to $3:(3=$ totally vital, normally active, no morphological changes, $2=$ slowed activity, first morphological changes and granularity visible, $1=$ minimal activity, severe morphological changes and granularity, $0=$ all worms dead, severe granularity) (Ramirez et al. 2007). For example, phenotypic changes following praziquantel incubation $(100 \mu \mathrm{g} / \mathrm{ml})$ for $72 \mathrm{~h}$ can be observed by means of light microscopy (Fig. 3c) and SEM (Fig. 3d). Blebbing, furrows, swelling, loss of structure and the lack of spines were visible following incubation with praziquantel. Since the assessment of morphological and behavioural responses of schistosomula to treatment is quite labour intensive and time consuming, the use of a drug response predictor (e.g. colourimetric assays, such as MTT formazan (3-(4,5-dimethylthiazol 2-yl)-2,5diphenyltetrazolium formazan), which measures the metabolic activity as a marker of viability in mammalian cell culture systems) should be explored. The latter assay technology might offer distinct advantages such as standardization, reproducibility and accuracy and can be performed more rapidly and easily, when compared to phenotypic evaluated drug screens.

\section{Adult S. mansoni in vitro assay}

In parallel to the development of schistosomula culture systems, culture methods for adult worms have been established (Clegg, 1965; Ramirez et al. 2007). Today, in vitro chemotherapeutic studies mainly rely on S. mansoni adults (Table 1, Fig. 2). For example, standard operating procedures (SOPs) for compound screening of the UNICEF/UNDP/ World Bank/WHO Special Programme for Research and Training in Tropical Diseases (TDR) are based on adult worms. Since the adult worm supply is somewhat restricted, the in vitro throughput capacity of this assay is limited $(\sim 2,000$ compounds are screened each year at TDR screening centers) (Ramirez et al. 2007). For this assay, mice are infected with a high number (up to 600) of S. mansoni cercariae. Adult S. mansoni are obtained by portal perfusion of mice after 40 days post-infection (Yolles et al. 1947; Smithers and Terry, 1965). 3-4 week old worms might also be used for in vitro studies (Hobbs et al. 1993) including drug sensitivity assays, as juvenile worms might show differences with regard to drug sensitivity when compared to larvae and adult worms. Following several washing steps, worms are incubated for example in DMEM, RPMI 1640 or HBSS supplemented with foetal calf serum, penicillin and streptomycin (Ramirez et al. 2007; Xiao et al. 2007). Schistosomes survive in a range of 
Table 1. In vitro drug screening: techniques employed, culture conditions and evaluation of juvenile and adult $S$. mansoni, F. hepatica and E. caproni assays

\begin{tabular}{|c|c|c|c|c|c|}
\hline Trematode & In vitro assays & Techniques employed & Culture media & Key issues & Evaluation of assay \\
\hline \multirow[t]{3}{*}{$\begin{array}{l}\text { Schistosoma } \\
\text { mansoni }\end{array}$} & $\begin{array}{l}\text { Newly } \\
\text { transformed } \\
\text { schistosomula }\end{array}$ & $\begin{array}{l}\text { Mechanical or chemical } \\
\text { transformation } \\
\text { of cercariae }\end{array}$ & $\begin{array}{l}\text { Different media possible, e.g. } \\
\text { Bash, MEM, DMEM, TC } \\
199 \text { supplemented with } \\
\text { penicillin and streptomycin } \\
\text { (and foetal calf serum) }\end{array}$ & $\begin{array}{l}\text { Cost-effective and ethical as } \\
\text { large numbers of schistosomula } \\
\text { can be obtained and no animals } \\
\text { needed. } \\
\text { Differences in drug sensitivity } \\
\text { between schistosomula and } \\
\text { adult worms? }\end{array}$ & \multirow[t]{2}{*}{$\begin{array}{l}\text { Microscopic assessment of } \\
\text { motility (viability score), } \\
\text { morphology and death of } \\
\text { worms. SEM and TEM } \\
\text { studies. }\end{array}$} \\
\hline & $\begin{array}{l}\text { Schistosomula } \\
\text { (juvenile } \\
\text { worms) }\end{array}$ & $\begin{array}{l}\text { Juvenile worms collected } \\
\text { from lungs of highly } \\
\text { infected mice } \\
\text { (infected with } 400-600 \\
\text { cercariae) }\end{array}$ & $\begin{array}{l}\text { Different media possible, } \\
\text { e.g.DMEM, RPMI } 1640 \text { or } \\
\text { Hanks' balanced salt solution } \\
\text { supplemented with foetal calf } \\
\text { serum, penicillin and }\end{array}$ & $\begin{array}{l}\text { Rarely used in } \\
\text { chemotherapeutic studies. }\end{array}$ & \\
\hline & $\begin{array}{l}\text { Juvenile } \\
\text { schistosomes } \\
\text { (3-4 week old) } \\
\text { Adult } \\
\text { schistosomes }\end{array}$ & $\begin{array}{l}\text { Perfusion of the portal } \\
\text { venous system of highly } \\
\text { infected mice (infected } \\
\text { with } 400-600 \text { cercariae) }\end{array}$ & streptomycin & $\begin{array}{l}\text { Need of animals. } \\
\text { Drug sensitivity assessed on } \\
\text { target parasite. }\end{array}$ & $\begin{array}{l}\text { Microscopic assessment of } \\
\text { motility (viability score), } \\
\text { morphology and death of } \\
\text { worms, inability to reduce } \\
\text { the tetrazolium, MTT. SEM } \\
\text { and TEM studies. }\end{array}$ \\
\hline \multirow[t]{3}{*}{ Fasciola hepatica } & $\begin{array}{l}\text { Newly excysted } \\
\text { juveniles }\end{array}$ & $\begin{array}{l}\text { Excystation of } \\
\text { metacercariae }\end{array}$ & $\begin{array}{l}\text { RPMI } 1640 \text { supplemented with } \\
\text { antibiotics (and serum or red } \\
\text { blood cells) }\end{array}$ & $\begin{array}{l}\text { Cost-effective and ethical as } \\
\text { large numbers of newly } \\
\text { excysted juveniles can be } \\
\text { obtained and no animals } \\
\text { needed. } \\
\text { Differences in drug sensitivity } \\
\text { between newly excysted } \\
\text { juveniles and adult worms } \\
\text { demonstrated. }\end{array}$ & $\begin{array}{l}\text { Microscopic assessment of } \\
\text { motility, morphology and } \\
\text { death of worms, inability to } \\
\text { reduce the tetrazolium, MTT. } \\
\text { SEM and TEM studies. }\end{array}$ \\
\hline & Juvenile worms & $\begin{array}{l}\text { Collection of worms from } \\
\text { rat or sheep livers }\end{array}$ & $\begin{array}{l}\text { NCTC } 135 \text { or RPMI } 1640 \\
\text { supplemented with antibiotics } \\
\text { (and serum or red blood cells) }\end{array}$ & $\begin{array}{l}\text { Need of animals. Drug } \\
\text { sensitivity assessed on target } \\
\text { parasite. }\end{array}$ & \multirow{2}{*}{$\begin{array}{l}\text { Microscopic assessment of } \\
\text { motility (viability score), } \\
\text { morphology and death of } \\
\text { worms. SEM and TEM } \\
\text { studies. }\end{array}$} \\
\hline & Adult worms & $\begin{array}{l}\text { Collection of worms from } \\
\text { the bile ducts of rats or } \\
\text { sheep }\end{array}$ & $\begin{array}{l}\text { NCTC } 135 \text { or RPMI } 1640 \\
\text { supplemented with antibiotics } \\
\text { (and serum or red blood cells) }\end{array}$ & $\begin{array}{l}\text { Need of animals. Drug } \\
\text { sensitivity assessed on target } \\
\text { parasite. }\end{array}$ & \\
\hline \multirow[t]{2}{*}{$\begin{array}{l}\text { Echinostoma } \\
\text { caproni }\end{array}$} & Juvenile worms & $\begin{array}{l}\text { Excystation of } \\
\text { metacercariae }\end{array}$ & $\begin{array}{l}\text { NCTC } 135 \text { supplemented with } \\
\text { antibiotics and serum or egg } \\
\text { yolk }\end{array}$ & $\begin{array}{l}\text { Cost effective and ethical as large } \\
\text { numbers of newly excysted } \\
\text { juveniles can be obtained and } \\
\text { no animals needed. }\end{array}$ & \multirow{2}{*}{$\begin{array}{l}\text { Microscopic assessment of } \\
\text { motility (viability score), } \\
\text { morphology and death of } \\
\text { worms. SEM and TEM } \\
\text { studies. }\end{array}$} \\
\hline & $\begin{array}{l}\text { Adult } \\
\text { echinostomes }\end{array}$ & $\begin{array}{l}\text { Collection of worms from } \\
\text { the intestine of highly } \\
\text { infected mice (up to } 300 \\
\text { metacercariae) }\end{array}$ & $\begin{array}{l}\text { RPMI } 1640 \text { supplemented with } \\
\text { antibiotics and glucose }\end{array}$ & Need of animals. & \\
\hline
\end{tabular}




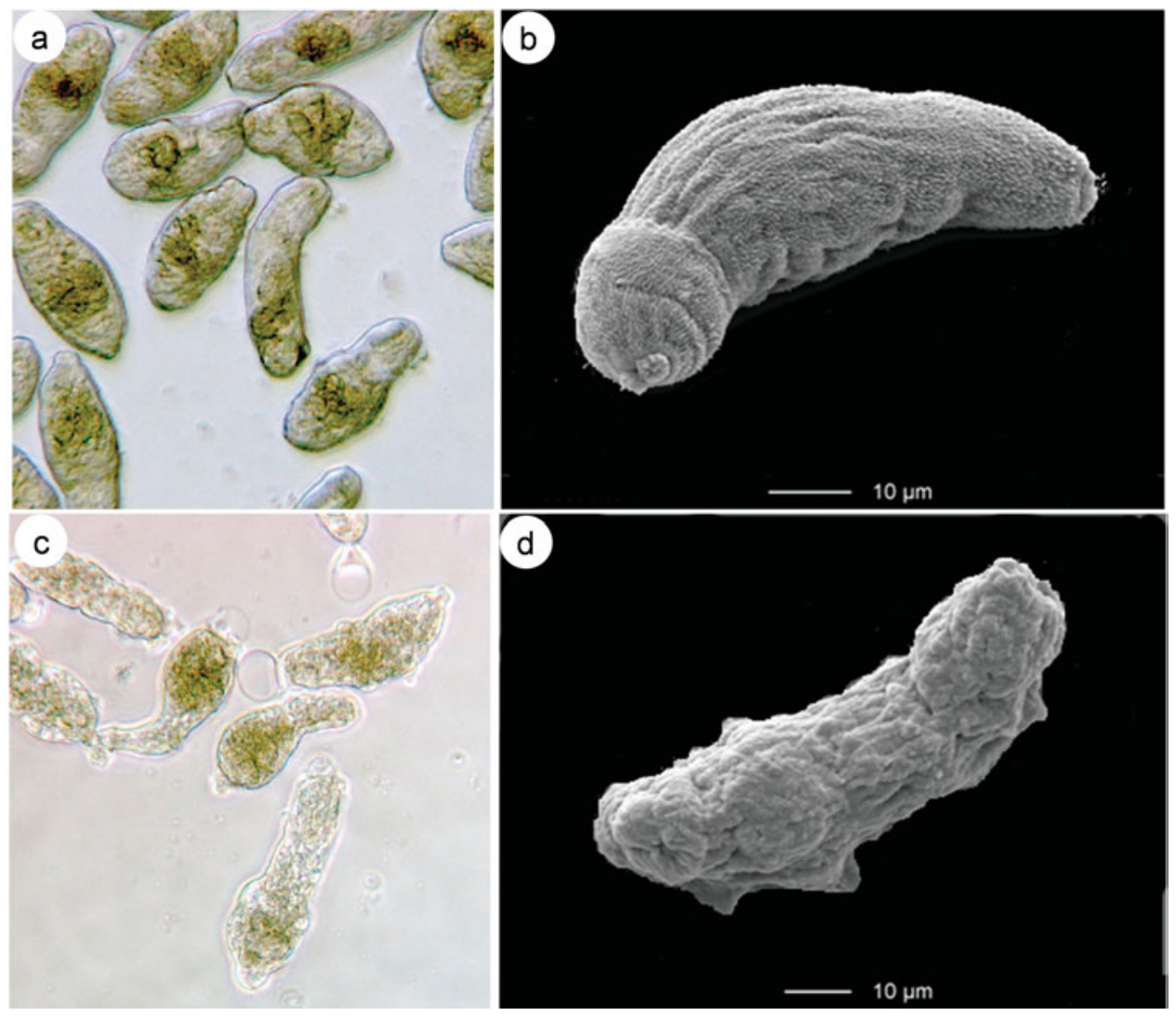

Fig. 3. Schistosoma mansoni- (a): light microscopic (LM) image of newly transformed control schistosomula. (b) SEM image of newly transformed control schistosomula. (c) LM image of newly transformed schistosomula incubated for $72 \mathrm{~h}$ in the presence of $100 \mu \mathrm{g} / \mathrm{ml}$ praziquantel (d) SEM image of newly transformed schistosomula incubated for $72 \mathrm{~h}$ in the presence of $100 \mu \mathrm{g} / \mathrm{ml}$ praziquantel.

supplemented tissue culture media for periods ranging from 3-120 days (Smyth and Halton, 1983). Test drugs at various concentrations $(5 \mu \mathrm{g} / \mathrm{ml}$ is the standard concentration in the primary screen at WHO-TDR screening centers (Ramirez et al. 2007)) are added to each culture well containing 6-10 worms. Worms are examined under a dissecting microscope at different time points (e.g. 24, 48 and $72 \mathrm{~h}$ ). Control schistosomes are incubated in the presence of the highest concentration of solvent used. Drug effects are commonly evidenced by phenotypic changes (motility and morphological changes and death) using an inverted microscope as described above. Markers such as MTT formazan have also been used to evaluate the viability of adult schistosomes (Oliveira et al. 2004). For more thorough studies on the effects of antischistosomal drugs, detailed surface features of treated and untreated specimens might be investigated by means of SEM as the tegument of trematodes is a highly susceptible site of damage following drug treatment (Manneck et al. 2009). For example, in Fig. 4b the male tegument is depicted. Fig. $4 \mathrm{c}$ shows the tegument of a male S. mansoni following drug treatment: $72 \mathrm{~h}$ post incubation with $100 \mu \mathrm{g} / \mathrm{ml}$ praziquantel blebbing was observed.

\section{S. mansoni in vivo model}

The mouse is the most commonly used mammalian host for experimental studies with $S$. mansoni (Table 2, Fig. 2). Though a difference has been observed regarding the percentage of cercariae that mature in different mouse strains, most mice strains tested were susceptible to an infection with $S$. mansoni (Lewis, 2001). 129/Ola and WEHI 129J mice are two examples of non-permissive hosts (Elsaghier et al. 1989). Hamsters (Xiao, et al. 2007), gerbils (Chisty et al. 2002), rabbits (Kasilima et al. 2004) or primates (Webbe et al. 1981) have also been used to study $S$. mansoni in vivo. The rat is only a semipermissive host (Cioli et al. 1977) and therefore unlikely to be suitable for the present purpose.

Animals are infected either by skin penetration, usually through the tail or shaved abdominal skin or via subcutaneous or intraperitonal injection of cercariae (Lewis, 2001). For chemotherapeutic studies it is important to compare the number of schistosomes in treated and untreated control animals, which is usually done after schistosomes have matured (6 to 8 weeks after infection).

Schistosomes are obtained and counted either via perfusion of the portal venous system (Yolles et al. 


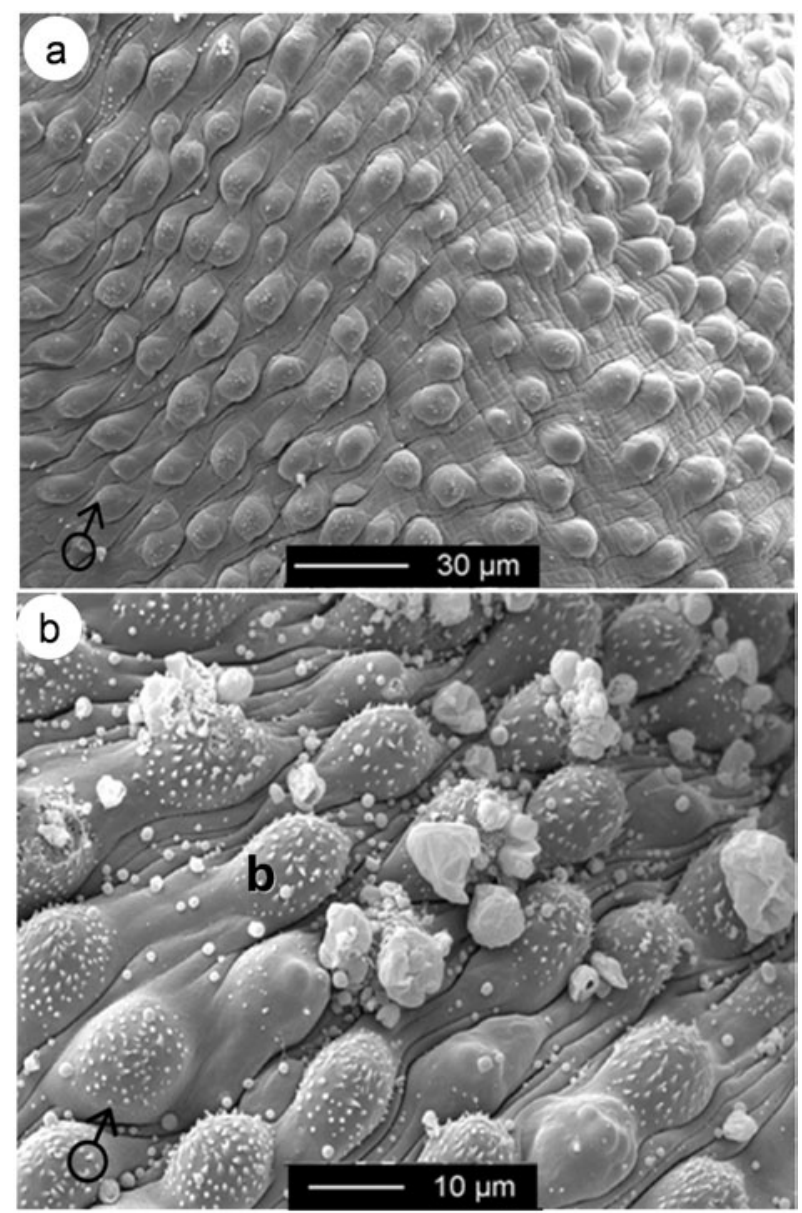

Fig. 4. Schistosoma mansoni-SEM observations. (a) dorsal male tegument and (b) blebbing (b) observed on the dorsal male tegument following incubation with $100 \mu \mathrm{g} / \mathrm{ml}$ praziquantel for $72 \mathrm{~h}$.

1947; Lewis, 2001) or examining the mesenteric veins and the liver for the presence of schistosomes (Xiao et al. 2007). In the latter case, the liver and the small and large intestines are removed from the animal. The liver is placed into a $20 \times 20 \mathrm{~cm}$ transparent plastic folder, compressed between 2 glass plates and the parenchyma is examined under a stereoscopic microscope. In addition, the mesenteric veins are systematically examined using a stereoscopic microscope. All schisosomes present in the liver and mesenteric veins are sexed and counted (Xiao et al. 2007).

To revisit our example of praziquantel, the current drug of choice, the in vivo antischistosomal properties of this drug have been well studied in the $S$. mansoni-mouse model. For example, a single $300 \mathrm{mg} / \mathrm{kg}$ oral dose of praziquantel resulted in a worm burden reduction of $81 \%$ (Xiao et al. 1999).

\section{FASCIOLA HEPATICA}

Fascioliasis is a major public health problem and an economically serious disease of livestock. Novel treatment options are of high priority as resistance to triclabendazole, the drug of choice in human and animal medicine, is spreading (Keiser et al. 2005; Fairweather, 2009). In addition, triclabendazole is licensed in only 4 countries (Keiser, et al. 2005). Chemotherapeutic studies have been undertaken with both $F$. hepatica and $F$. gigantica, although the former species has been more extensively studied.

The life cycle of Fasciola spp. is maintained at several research laboratories, universities and private companies (Fig. 1), where metacercariae (different triclabendazole-resistant and -sensitive isolates) can be obtained or purchased. Briefly, the lymnaeid snails Galba spp. and Fossaria spp. mainly act as intermediate hosts (Mas-Coma et al. 2007). Infection in humans and animals occur through the ingestion of metacercariae attached to water vegetables or in contaminated water (Keiser et al. 2005; Mas-Coma et al. 2007; Keiser and Utzinger, 2009). In experimental infections laboratory animals are exposed to metacercariae by stomach tube or oesophageal intubation, while a gelatin bolus or capsule containing the metacercariae are often used to infect sheep (Clery et al. 1995). In the intestine the fluke excysts (newly excysted juvenile), penetrates the gut wall and enters the body cavity. After wandering over the viscera the juvenile flukes reach the liver. For several weeks the juvenile flukes burrow through the liver causing hemorrhage, tissue destruction and destruction of the liver cells. Approximately 8 weeks after infection $F$. hepatica reach the bile ducts, where they continue to grow and develop into adults, reaching full size by 12-14 weeks after infection (Anderson and Fairweather, 1995; Fairweather et al. 1999). Due to the massive damage of the migrating juvenile stages of the parasite, an ideal fasciolicidal drug should be active against both parasite stages, as is triclabendazole (Keiser et al. 2005 ; Fairweather, 2009).

\section{F. hepatica in vitro assays}

Newly encysted juveniles, young and adult worms can be cultured in vitro (Fig. 5, Table 1). An assay based on newly excysted juveniles offers the advantage that, as for the schistosomula assay described above, a mammalian host is not required. Metacarcariae excyst when exposed to appropriate stimuli (Dixon, 1966). Commonly used SOPs include exposure of metacercariae to an activation medium followed by incubation in an emergence medium. For example, the following protocol has been described by McGonigle and colleagues: metacercariae are excysted by incubation in $0.5 \%$ sodium hypochlorite for $20 \mathrm{~min}$ prior to centrifugation (2000 $\mathrm{g}$ for $2 \mathrm{~min}$ ), washing in distilled water and incubation in $0.5 \%$ sodium bicarbonate, $0.4 \%$ sodium chloride, $0 \cdot 2 \%$ sodium tauroglycholate, $0.07 \%$ concentrated $\mathrm{HCl}$ and $0.006 \%$ l-cysteine for up to $3 \mathrm{~h}$ at $37^{\circ} \mathrm{C}$ (McGonigle et al. 2008). Excysted juveniles are maintained in nutritive culture medium, such as 


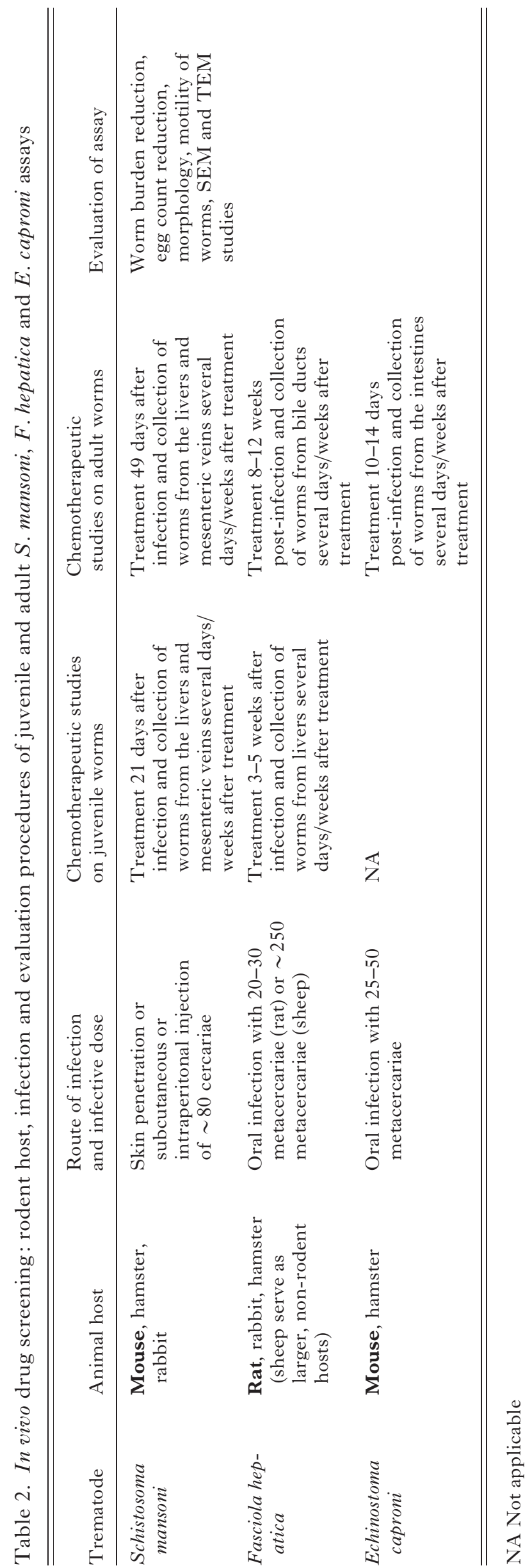

RPMI 1640, supplemented with penicillin and streptomycin and possibly serum or red blood cells (Ibarra and Jenkins, 1984). In vitro assays based on newly excysted flukes have been used to study the fasciolicidal activities of investigational compounds; for example, 20 plant extracts were recently evaluated using this parasite stage (Vera-Montenegro et al. 2008). Nonetheless, newly excysted flukes might have different drug sensitivities when compared to juvenile and adult flukes: a study which compared the fasciolicidal activity of known fasciolicides demonstrated that newly excysted flukes were unaffected by most of these compounds (Ibarra and Jenkins, 1984).

Assays based on juvenile or adult Fasciola are more often used to study fasciolicidal properties of investigational drugs in vitro. The main disadvantages of these assays are that only few flukes can be recovered from the laboratory rat, which is the main rodent host. Rats tolerate an infective dose of 20-30 metacercariae, yielding between 2 and 13 mature flukes (Chapman and Mitchell, 1982). In addition, as mentioned above, Fasciola spp. grow for 8-12 weeks until they are fully mature. Hence, these assays are expensive and time consuming. Another possibility to obtain parasite material in a more efficient and less costly manner in endemic countries is to collect worms from animals slaughtered in abattoirs (Shalaby et al. 2009). Juvenile or adult Fasciola are incubated in the presence of RPMI 1640 or NTCT 135, supplemented with antibiotics and the investigational drug (Anderson and Fairweather, 1995; Keiser et al. 2006). Though supplementation of the medium with serum is recommended for long term culture of Fasciola spp. (longer than 4 days), serum substitution may not be advised for Fasciola drug activity studies, as many drugs bind strongly to serum proteins (Jenkins et al. 1987). Fasciolicidal drugs such as rafoxanide or bithionol showed a decreased activity in vitro in the presence of serum compared to serumless medium (Jenkins et al. 1987). The presence of bile in the incubation medium has also been shown to influence the uptake pattern of fasciolicidal drugs, such as triclabendazole or albendazole (Alvarez et al. 2004). As described above for the schistosomes, fasciolicidal properties are examined documenting motility, morphological changes and death. To my knowledge metabolic markers have not been used in Fasciola drug sensitivity assays. Drug effects have also been well documented using SEM and transmission electron microscopy (TEM) (Anderson and Fairweather, 1995; McConville et al. 2006; Keiser and Morson, 2008). For example, Fig. 6a shows a SEM image of the anterior region of a $F$. hepatica. We have recently described that the semi-synthetic artemisinin derivatives artemether and artesunate, which are essential components of malaria therapy (White, 2008) and synthetic derivatives possess a broad range of trematodicidal activities (Keiser and 


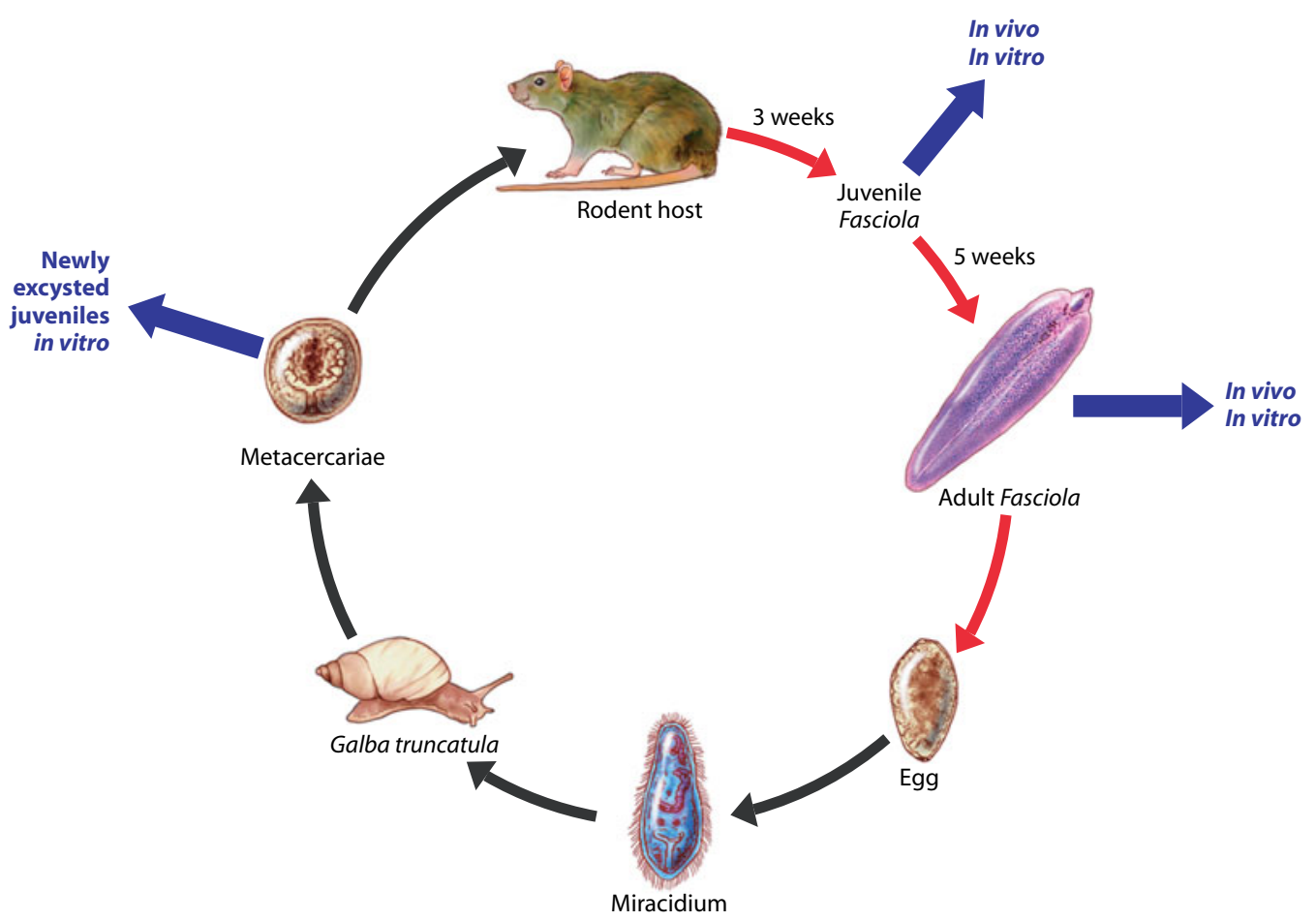

Fig. 5. Life cycle of $F$. hepatica highlighting collection points for in vitro and in vivo chemotherapeutic studies. Maturation of parasite occurs within final host (red arrows).
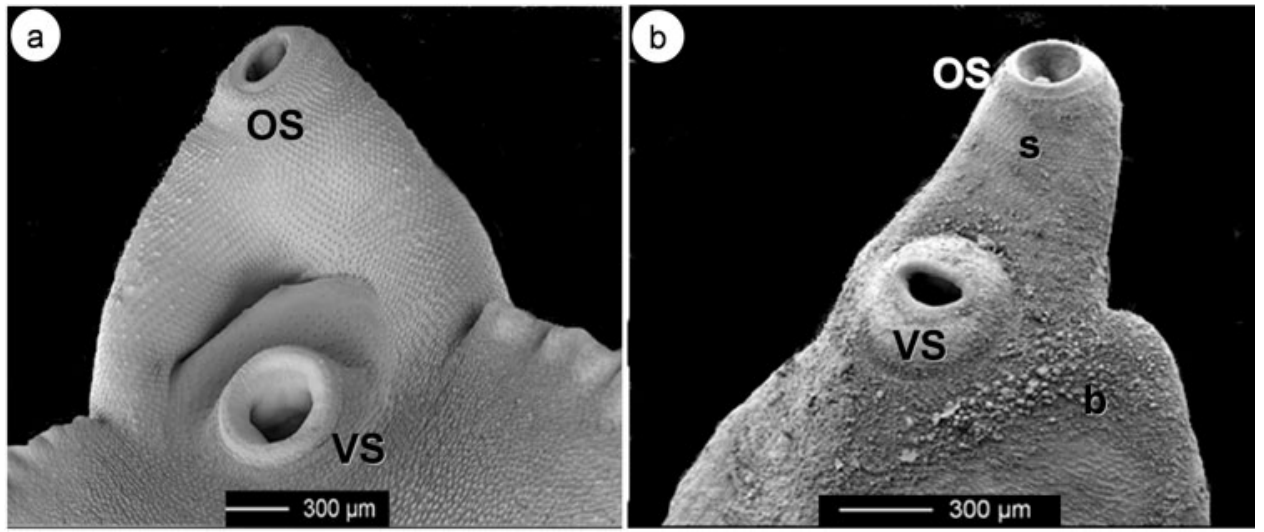

Fig. 6. Fasciola hepatica-SEM observations. (a) anterior region of an adult $F$. hepatica recovered from a rat (OS: oral sucker, VS: ventral sucker). (b) Blebbing (b) and sloughing (s) visible near the ventral sucker (VS) on a $F$. hepatica recovered from a rat $48 \mathrm{~h}$ post-treatment with a single oral dose of $200 \mathrm{mg} / \mathrm{kg}$ artemether.

Utzinger, 2007; Utzinger et al. 2007). Fig. 6b depicts the head region of a Fasciola fluke 48 h post-treatment with a single $200 \mathrm{mg} / \mathrm{kg}$ oral dose of artemether, revealing blebbing, sloughing and roughening of the tegumental surface (Keiser and Morson, 2008).

\section{F. hepatica in vivo assays}

$F$. hepatica can be grown in different laboratory animals but, as mentioned above, the rat is the most commonly used rodent to study $F$. hepatica in vivo (Fig. 5, Table 2). No significant difference was observed between different rats strains infected with $F$. hepatica with regard to worm burden (Chapman and Mitchell, 1982). Rats, commonly infected with
20-30 metacercariae, harbour between 2-13 adult flukes (Chapman and Mitchell, 1982). The laboratory mouse is not a suitable model to grow adult $F$. hepatica, as mortality of mice is high and the flukes do not fully develop in this model (Chapman and Mitchell,1982; Smyth and Halton, 1983). The infectivity of $F$. gigantica was found to be low in Wistar rats (Itagaki et al. 1994). Rabbits, the rat-like hamster, Tscherskia triton, and sheep have also been used for studies of experimental fascioliasis (Terasaki et al. 2003; McConville et al. 2009).

In chemotherapeutic studies, groups of rats or sheep, which had been experimentally infected with $F$. hepatica for 3-5 weeks (juvenile infection) and 8-12 weeks (adult infection) or sheep harbouring a 


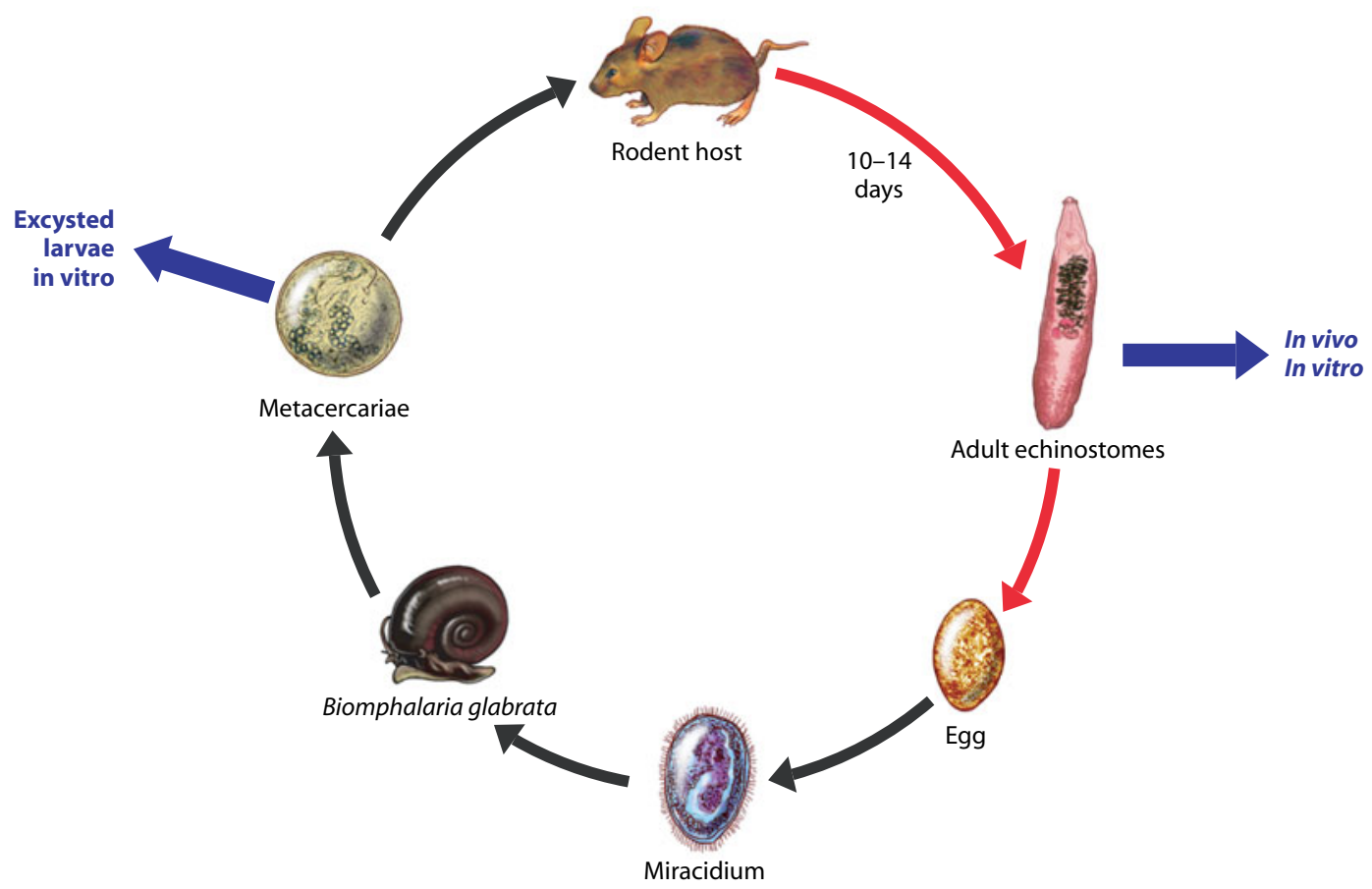

Fig. 7. Life cycle of E. caproni highlighting collection points for in vitro and in vivo chemotherapeutic studies. Maturation of parasite occurs within final host (red arrow).

natural infection are treated with the investigational drugs and the numbers of flukes present in the livers and bile ducts are counted several weeks post treatment. Groups of untreated animals serve as controls (Keiser et al. 2006, 2008; McConville et al. 2009). Besides the effect of the drug on the Fasciola worm burden, the egg count reduction and the effect of the drug on the morphology, tegument or intestinal structures are studied (McKinstry et al. 2003; Keiser and Morson, 2008; McConville et al. 2009).

Revisiting the artemisinins, the fasciolicidal properties of artemether were thoroughly studied in $F$. hepatica-infected rats (both a triclabendazoleresistant and -sensitive isolate) and sheep harbouring a natural $F$. hepatica infection : single oral artemether at $200 \mathrm{mg} / \mathrm{kg}$ achieved a complete cure in rats (Keiser et al. 2006, 2007), while a worm burden reduction of $91 \%$ was recorded in sheep following a single intramuscular administration of $160 \mathrm{mg} / \mathrm{kg}$ artemether (Keiser et al. 2008).

\section{ECHINOSTOMA CAPRONI}

The third example is the intestinal fluke E. caproni, which has been widely used as an experimental model in different areas of research, as its life cycle is easy to maintain in the laboratory (Fried and Huffman, 1996). Laboratories, which maintain this life cycle are depicted in Fig. 1. Echinostomes invade domestic animals, wildlife or humans (Toledo and Fried, 2005). The rodent and the avian fluke $E$. caproni cycles between $B$. glabrata snails and laboratory mice (Fig. 7) (Fried and Huffman, 1996).
Briefly, mice are infected orally with 25-50 metacercariae, though up to 300 metacercariae are tolerated (Platt, 2009). An adult infection is established $\sim 2$ weeks after infection. For life cycle maintenance, eggs can be removed either directly from the worms collected from mice intestines or faeces. After embryonation of eggs for about 14-17 days at room temperature miracidia develop. Biomphalaria glabrata are exposed to fully developed eggs or miracidia (Idris and Fried, 1996). Four to six weeks after infection of snails, most snails in the aquarium contain hundreds of metacercariae in the pericardial kidney region (Fried and Huffman, 1996).

\section{E. caproni in vitro assay}

Encysted metacercariae of E caproni can be excysted in a trypsin-bile salts-cysteine medium (Table 1) (Saxton et al. 2008; Fried and Peoples, 2009). Excysted larvae have been mainly used in in vitro culture studies and might also prove useful for chemotherapeutic, biological or physiological studies as reviewed elsewhere (Fried, 1994). Excysted larvae are cultured in a defined medium such as NCTC 135 supplemented with antibiotics and different types of natural products such as serum, egg yolk or mucus (Fried, 2000).

Several studies have examined the echinostomicidal properties of investigational drugs using adult echinostomes in vitro (Leger et al. 1973; Leger and Notteghem, 1975; Keiser et al. 2006). Though adult echinostomes maintained in vitro deteriorate quickly, possibly due to microbial contamination and/or 


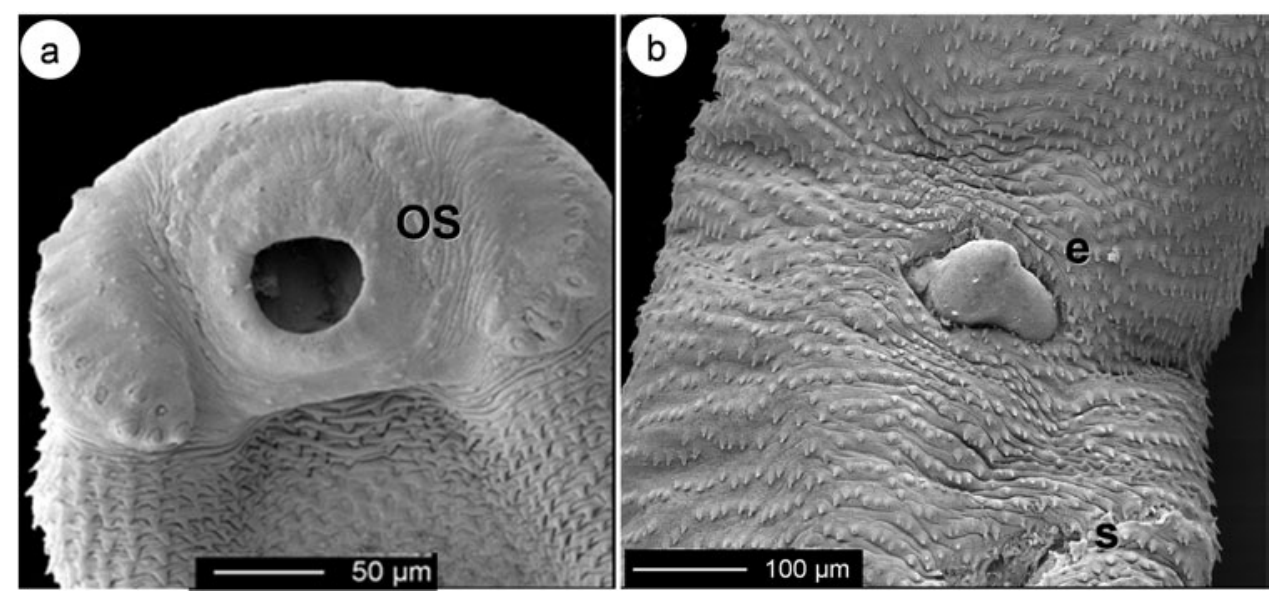

Fig 8. Echinostoma caproni-SEM observations. (a) anterior region of an adult E. caproni recovered from a mouse. (b) eruption (e) and sloughing (s) visible on the ventral surface of an E. caproni 4 h post-treatment with a single oral dose of $700 \mathrm{mg} / \mathrm{kg}$ artesunate.

worm autolysis (Fried, 2000), echinostomes can be maintained in nutritive media such as RPMI 1640 ideally supplemented with additional glucose (e.g. $1 \%$ ) for several days (Leger et al. 1973). As described above worms incubated in the presence of drugs are analyzed for occurrence of death, motility disturbances or morphological changes.

\section{E. caproni in vivo assay}

While there is a high degree of compatibility between E. caproni and mice and hamsters, rats show a low degree of compatibility with E. caproni (Toledo and Fried, 2005). E. caproni can survive for more than 20 weeks in mice and hamsters (Toledo and Fried, 2005). The laboratory mouse is most commonly used to study E. caproni in vivo (Table 2). As adult infections are established already by $10-14 \mathrm{~d}$ after infection, this model allows for quicker patent infections in the definitive hosts than the $F$. hepatica or $S$. mansoni assays described above. Hence, results are obtained rapidly and cost-effectively in the E. caproni-mouse model. In vivo studies in Echinostoma spp. infected mice, with various test compounds such as the benzimidazoles, praziquantel, the artemisinins or tribendimidine against echinostomes in mice have been summarized recently (Saric et al. 2009). For example, E. caproni-infected mice were cured following a single oral dose of $700 \mathrm{mg} / \mathrm{kg}$ artesunate (Keiser et al. 2006). In Fig. 8a the head region of an untreated E. caproni is depicted. Four h after treatment with a single $700 \mathrm{mg} / \mathrm{kg}$ oral dose of artesunate eruption and sloughing was observed on the ventral surface of an E. caproni fluke (Fig. 8b) (Keiser et al. 2006)

\section{CONCLUSION}

Schistosomiasis and food-borne trematodiases are chronic parasitic diseases affecting millions of people, mostly in the developing world. The number of drugs available to treat these diseases is surprisingly small and preliminary reports of resistance in the field and laboratory highlight the need to develop new trematodicidal drugs (Colley et al. 2001 ; Caffrey 2007 ; Keiser and Utzinger, 2009). In vitro and in vivo whole parasite screens represent essential components of the trematodicidal drug discovery cascade in particular as molecular-based target drug screening approaches are still very limited. Nonetheless, publications of latest draft genome sequences e.g. for schistosomes (Berriman et al. 2009; Liu et al. 2009) will provide new insights into the biology of trematodes and offer an opportunity for identification of potential drug targets. For example, 71,028 compounds were recently screened for thioredoxin/ glutathione reductase and peroxiredoxin activity, principal components of the defence system of schistosomes (Cioli et al. 2008; Simeonov et al. 2008). Efforts to enter novel molecular targets in the trematodicidal drug-discovery process should go hand-in-hand with an improvement of existing whole organism screens. Validated, robust, high throughput in vitro systems are needed to boost the discovery pipeline for these diseases (Colley et al. 2001). Difficulties still need to be overcome in the basic cultivation of trematodes. In addition, phenotypic assessment of treated parasites is still the method of choice in in vitro drug screens and the development of simple readouts that are amenable to automated analysis (e.g. calorimetric analysis, viability markers) would be a great step forward.

\section{ACKNOWLEDGEMENTS}

I am grateful to the Swiss National Science Foundation for a personal career development grant (project no. PPOOA114941). Thanks are addressed to Prof. Bernard Fried to comments on the E. caproni section, to Prof. Jürg Utzinger 
for carefully reading a draft version of this manuscript and stimulating discussions and to Patrick Lane for the excellent work enhancing the figures.

\section{REFERENCES}

Abdulla, M. H., Ruelas, D. S., Wolff, B., Snedecor, J., Lim, K. C., Xu, F., Renslo, A. R., Williams, J., McKerrow, J. H. and Caffrey, C. R. (2009). Drug discovery for schistosomiasis: hit and lead compounds identified in a library of known drugs by medium-throughput phenotypic screening. PLoS Neglected Tropical Diseases 3, e478.

Agnew, A. M., Murare, H. M., Lucas, S. B. and Doenhoff, M. J. (1989). Schistosoma bovis as an immunological analogue of $S$. haematobium. Parasite Immunology 11, 329-340.

Alvarez, L. I., Mottier, M. L. and Lanusse, C. E. (2004). Comparative assessment of the access of albendazole, fenbendazole and triclabendazole to Fasciola hepatica: effect of bile in the incubation medium. Parasitology 128, 73-81.

Anderson, H. R. and Fairweather, I. (1995). Fasciola hepatica: ultrastructural changes to the tegument of juvenile flukes following incubation in vitro with the deacetylated (amine) metabolite of diamphenethide. International Fournal for Parasitology 25, 319-333.

Basch, P. F. (1981). Cultivation of Schistosoma mansoni in vitro. I. Establishment of cultures from cercariae and development until pairing. Fournal of Parasitology 67, 179-185.

Berriman, M., Haas, B. J., LoVerde, P. T., Wilson, R. A., Dillon, G. P., Cerqueira, G. C., Mashiyama, S. T., Al-Lazikani, B., Andrade, L. F., Ashton, P. D., Aslett, M. A., Bartholomeu, D. C., Blandin, G., Caffrey, C. R., Coghlan, A., Coulson, R., Day, T. A., Delcher, A., DeMarco, R., Djikeng, A., Eyre, T., Gamble, J. A., Ghedin, E., Gu, Y., Hertz-Fowler, C., Hirai, H., Hirai, Y., Houston, R., Ivens, A., Johnston, D. A., Lacerda, D., Macedo, C. D., McVeigh, P., Ning, Z., Oliveira, G., Overington, J. P., Parkhill, J., Pertea, M., Pierce, R. J., Protasio, A. V., Quail, M. A., Rajandream, M. A., Rogers, J., Sajid, M., Salzberg, S. L., Stanke, M., Tivey, A. R., White, O., Williams, D. L., Wortman, J., Wu, W., Zamanian, M., Zerlotini, A., Fraser-Liggett, C. M., Barrell, B. G. and El-Sayed, N. M. (2009). The genome of the blood fluke Schistosoma mansoni. Nature 460, 352-358.

Brink, L. H., McLaren, D. J. and Smithers, S. R. (1977). Schistosoma mansoni: a comparative study of artificially transformed schistosomula and schistosomula recovered after cercarial penetration of isolated skin. Parasitology 74, 73-86.

Broadhead, C. L. and Bottrill, K. (1997). Strategies for replacing animals in biomedical research. Molecular Medicine Today 3, 483-487.

Caffrey, C. R. (2007). Chemotherapy of schistosomiasis: present and future. Current Opinion in Chemical Biology 11, 433-439.

Caffrey, C. R., Williams, D. L., Todd, M. H., Nelson, D. L., Keiser, J. and Utzinger, J. (2009).

Chemotherapeutic development strategies for schistosomiasis. In Drug Discovery in Infectious Diseases: From Molecular Targets to Drug Candidates, (ed. P. M. Selzer.), pp. 301-321 Wiley, Weinheim, Germany.

Chapman, C. B. and Mitchell, G. F. (1982). Fasciola hepatica: comparative studies on fascioliasis in rats and mice. International Fournal for Parasitology $\mathbf{1 2}$, 81-91.

Chisty, M. M., Nargis, M., Sato, H., Inaba, T., Takahashi, G. and Kamiya, H. (2002). Schistosoma mansoni: kinetics of glomerulonephritis in Mongolian gerbils and its correlation with intensity and duration of infection. Parasite 9, 143-151.

Cioli, D., Knopf, P. M. and Senft, A. W. (1977). A study of Schistosoma mansoni transferred into permissive and nonpermissive hosts. International Fournal for Parasitology 7, 293-297.

Cioli, D., Valle, C., Angelucci, F. and Miele, A. E. (2008). Will new antischistosomal drugs finally emerge? Trends in Parasitology 24, 379-382.

Clegg, J. A. (1965). In vitro cultivation of Schistosoma mansoni. Experimental Parasitology 16, 133-147.

Clery, D. G., O’Mahony, P. and Mulcahy, G. (1995). A novel method for the administration of metacercariae of Fasciola hepatica to adult cattle. Research in Veterinary Science 58, 290-291.

Colley, D. G. and Wikel, S. K. (1974). Schistosoma mansoni: simplified method for the production of schistosomules. Experimental Parasitology 35, 44-51.

Colley, D. G., LoVerde, P. T. and Savioli, L. (2001). Medical Helminthology in the 21st Century. Science 293, 1437-1438.

Cox, F. E. G. (1993). Modern Parasitology. Blackwell Scientific Publications, Oxford.

Davis, A. 2009. Schistosomiasis, p. 1413-1456. In Manson's Tropical Diseases, 22nd Edition. (ed. G. C. Cook and A. I. Zumla) Saunders, London.

Dixon, K. E. (1966). The physiology of excystment of the metacercaria of Fasciola hepatica L. Parasitology 56, 431-456.

Doenhoff, M. J., Hagan, P., Cioli, D., Southgate, V., Pica-Mattoccia, L., Botros, S., Coles, G., Tchuem Tchuente, L. A., Mbaye, A. and Engels, D. (2009). Praziquantel: its use in control of schistosomiasis in sub-Saharan Africa and current research needs. Parasitology, 136, 1825-1835.

Elsaghier, A. A., Knopf, P. M., Mitchell, G. F. and McLaren, D. J. (1989). Schistosoma mansoni: evidence that 'non-permissiveness' in 129/Ola mice involves worm relocation and attrition in the lungs. Parasitology 99, 365-375.

Fairweather, I. (2009). Triclabendazole progress report, 2005-2009: an advancement of learning? Fournal of Helminthology 83, 139-150.

Fairweather, I., Threadgold, L. T. and Hanna, R. E. B. (1999). Development of Fasciola hepatica in the mammalian host. In Fasciolosis. (ed. J. P. Dalton) CABI Publishing, pp. 225-276.

Fried, B. (1994). Metacercarial excystment of trematodes. Advances in Parasitology 33, 91-144.

Fried, B. (2000). Maintenance, cultivation, and excystation of echinostomes. In Echinostomes as Experimental Models for Biological Research (ed. B. Fried and T. Graczyk) Kluwer Academic Publishers, pp. 99-118. 
Fried, B. and Huffman, J. E. (1996). The biology of the intestinal trematode Echinostoma caproni. Advances in Parasitology 38, 311-368.

Fried, B. and Peoples, R. C. (2009). Maintenance, cultivation and excystation of echinostomes : 2000-2007. In The Biology of Echinostomes. (ed. B. Fried and R. Toledo) Springer, New York, 111-128.

Gryseels, B., Polman, K., Clerinx, J. and Kestens, L. (2006). Human schistosomiasis. Lancet $\mathbf{3 6 8}$, 1106-1118.

Hobbs, D. J., Fryer, S. E., Duimstra, J. R., Hedstrom, O. R., Brodie, A. E., Collodi, P. A., Menino, J. S., Bayne, C. J. and Barnes, D. W. (1993). Culture of cells from juvenile worms of Schistosoma mansoni. Fournal of Parasitology 79, 913-921.

Hotez, P. J., Fenwick, A., Savioli, L. and Molyneux, D. H. (2009). Rescuing the bottom billion through control of neglected tropical diseases. Lancet 373, 1570-1575.

Howells, R. E., Ramalho-Pinto, F. J., Gazzinelli, G., de Oliveira, C. C., Figueiredo, E. A. and Pellegrino, J. (1974). Schistosoma mansoni: mechanism of cercarial tail loss and its significance to host penetration. Experimental Parasitology 36, 373-385.

Ibarra, O. F. and Jenkins, D. C. (1984). An in vitro screen for new fasciolicidal agents. Zeitschrift für Parasitenkunde 70, 655-661.

Idris, N. and Fried, B. (1996). Development, hatching, and infectivity of Echinostoma caproni (Trematoda) eggs, and histologic and histochemical observations on the miracidia. Parasitology Research 82, 136-142.

Itagaki, T., Sakamoto, T., Tsutsumi, Y. and Itagaki, H. (1994). Infectivity of three species of Fasciola to Wistar rats. Fournal of Veterinary Medical Science 56, 977-979.

Jenkins, D. C., Topley, P. and Rapson, E. B. (1987). Fasciola hepatica in vitro: increased susceptibility to fasciolicides in a defined serum-free medium. Parasitology 95, 165-171.

Kasilima, Y. S., Wango, E. O., Kigondu, C. S., Mutayoba, B. M. and Nyindo, M. (2004). Plasma bioactive LH and testosterone profiles in male New Zealand rabbits experimentally infected with Schistosoma mansoni. Acta Tropica 92, 165-172.

Keiser, J., Brun, R., Fried, B. and Utzinger, J. (2006). Trematocidal activity of praziquantel and artemisinin derivatives: in vitro and in vivo investigations on adult Echinostoma caproni. Antimicrobial Agents and Chemotherapy 50, 803-805.

Keiser, J., Engels, D., Büscher, G. and Utzinger, J. (2005). Triclabendazole for the treatment of fascioliasis and paragonimiasis. Expert Opinion of Investigational Drugs 14, 1513-1526.

Keiser, J. and Morson, G. (2008). Fasciola hepatica: tegumental alterations in adult flukes following in vitro and in vivo administration of artesunate and artemether. Experimental Parasitology 118, 228-237.

Keiser, J., Rinaldi, L., Veneziano, V., Mezzino, L., Tanner, M., Utzinger, J. and Cringoli, G. (2008). Efficacy and safety of artemether against a natural Fasciola hepatica infection in sheep. Parasitology Research 103, 517-522.
Keiser, J. and Utzinger, J. (2004). Chemotherapy for major food-borne trematodes: a review. Expert Opinion on Pharmacotherapy 5, 1711-1726.

Keiser, J. and Utzinger, J. (2005). Emerging foodborne trematodiasis. Emerging Infectious Diseases 11, $1507-1514$.

Keiser, J. and Utzinger, J. (2007). Food-borne trematodiasis: current chemotherapy and advances with artemisinins and synthetic trioxolanes. Trends in Parasitology 23, 555-562.

Keiser, J. and Utzinger, J. (2009). Food-borne trematodiases. Clinical Microbiology Reviews 22, 466-483.

Keiser, J., Utzinger, J., Tanner, M., Dong, Y. and Vennerstrom, J. L. (2006). The synthetic peroxide OZ78 is effective against Echinostoma caproni and Fasciola hepatica. Fournal of Antimicrobial Chemotherapy 58, 1193-1197.

Keiser, J., Utzinger, J., Vennerstrom, J. L., Dong, Y., Brennan, G. and Fairweather, I. (2007). Activity of artemether and OZ78 against triclabendazole-resistant Fasciola hepatica. Transactions of the Royal Society of Tropical Medicine and Hygiene 101, 1219-1222.

Keiser, J., Xiao, S. H., Tanner, M. and Utzinger, J. (2006). Artesunate and artemether are effective fasciolicides in the rat model and in vitro. Fournal of Antimicrobial Chemotherapy 57, 1139-1145.

Leger, N. and Notteghem, M. J. (1975). The fasciolidal activity of a new compound, brotianide on Echinostoma caproni Richard 1964. Annales Pharmaceutiques Françaises 33, 273-277.

Leger, N., Notteghem, M. J. and Cavier, R. (1973). Un test pharmacodynamique pour l'essai des douvicides. Bulletin de la Societe de Pathologie Exotique 66, 732-736.

Lewis, F. (2001). Schistosomiasis. Current Protocols in Immunology 19, Unit 19.1.

Liu, F., Zhou, Y., Wang, Z. Q., Lu, G., Zheng, H., Brindley, P. J., McManus, D. P., Blair, D., Zhang, Q. H., Zhong, Y., Wang, S., Han, Z. G. and Chen, Z. (2009). The Schistosoma japonicum genome reveals features of host-parasite interplay. Nature $\mathbf{4 6 0}$, 345-351.

Manneck, T., Haggenmüller, Y. and Keiser, J. (2009). Morphological effects and tegumental alterations induced by mefloquine on schistosomula and adult flukes of Schistosoma mansoni. Parasitology 136,

Mas-Coma, S., Bargues, M. D. and Valero, M. A. (2007). Plant-borne trematode zoonoses: fascioliasis and fasciolopsiasis. In Food-Borne Parasitic Zoonoses (ed. K. D. Murrell and B. Fried ) Springer, New York, pp. 293-334.

McConville, M., Brennan, G. P., Flanagan, A., Edgar, H. W., Hanna, R. E., McCoy, M., Gordon, A. W., Castillo, R., Hernandez-Campos, A. and Fairweather, I. (2009). An evaluation of the efficacy of compound alpha and triclabendazole against two isolates of Fasciola hepatica. Veterinary Parasitology 162, $75-88$.

McConville, M., Brennan, G. P., McCoy, M., Castillo, R., Hernandez-Campos, A., Ibarra, F. and Fairweather, I. (2006). Adult triclabendazole-resistant Fasciola hepatica: surface and subsurface tegumental responses to in vitro treatment with the sulphoxide 
metabolite of the experimental fasciolicide compound alpha. Parasitology, 133, 195-208.

McGonigle, L., Mousley, A., Marks, N. J., Brennan, G. P., Dalton, J. P., Spithill, T. W., Day, T. A. and Maule, A. G. (2008). The silencing of cysteine proteases in Fasciola hepatica newly excysted juveniles using RNA interference reduces gut penetration. International Fournal for Parasitology 38, 149-155.

McKinstry, B., Fairweather, I., Brennan, G. P. and Forbes, A. B. (2003). Fasciola hepatica: tegumental surface alterations following treatment in vivo and in vitro with nitroxynil (Trodax). Parasitology Research 91, 251-263.

Melman, S. D., Steinauer, M. L., Cunningham, C., Kubatko, L. S., Mwangi, I. N., Wynn, N. B., Mutuku, M. W., Karanja, D. M., Colley, D. G., Black, C. L., Secor, W. E., Mkoji, G. M. and Loker, E. S. (2009). Reduced susceptibility to praziquantel among naturally occurring Kenyan isolates of Schistosoma mansoni. PLoS Neglected Tropical Diseases 3, e504.

Oliveira, M. F., d'Avila, J. C., Tempone, A. J., Soares, J. B., Rumjanek, F. D., Ferreira-Pereira, A., Ferreira, S. T. and Oliveira, P. L. (2004). Inhibition of heme aggregation by chloroquine reduces Schistosoma mansoni infection. Fournal of Infectious Diseases 190, 843-852.

Platt, T. R. (2009). The course of a 300 metacercarial infection of Echinostoma caproni (Digenea: Echinostomatidae) in Institute for Cancer Research (ICR) mice. Comparative Parasitology 76, 1-5.

Ramalho-Pinto, F. J., Gazzinelli, G., Howells, R. E., Mota-Santos, T. A., Figueiredo, E. A. and Pellegrino, J. (1974). Schistosoma mansoni: defined system for stepwise transformation of cercaria to schistosomule in vitro. Experimental Parasitology 36, 360-372.

Ramirez, B., Bickle, Q., Yousif, F., Fakorede, F., Mouries, M. A. and Nwaka, S. (2007). Schistosomes: Challenges in drug screening. Expert Opinion on Drug Discovery 2, 53-61.

Renslo, A. R. and McKerrow, J. H. (2006). Drug discovery and development for neglected parasitic diseases. Nature Chemical Biology 2, 701-710.

Ridley, R. G. and Kita, K. (2007). Helminth Drug Initiative. Expert Opinion on Drug Discovery 2, 1.

Saric, J., Li, J. V., Wang, Y., Holmes, E., Utzinger, J. and Keiser, J. (2009). Use of Echinostoma spp. in studies on chemotherapy and metabolic profiling. In The Biology of Echinostomes (ed. B. Fried and R. Toledo) Springer, New York, pp. 295-320.

Saxton, T. M., Fried, B. and Peoples, R. C. (2008). Excystation of the encysted metacercariae of Echinostoma trivolvis and Echinostoma caproni in a trypsin-bile salts-cysteine medium and morphometric analysis of the excysted larvae. Fournal of Parasitology 94, 669-671.

Sayed, A. A., Simeonov, A., Thomas, C. J., Inglese, J., Austin, C. P. and Williams, D. L. (2008).

Identification of oxadiazoles as new drug leads for the control of schistosomiasis. Nature Medicine 14, 407-412.

Shalaby, H. A., El Namaky, A. H. and Kamel, R. O. (2009). In vitro effect of artemether and triclabendazole on adult Fasciola gigantica. Veterinary Parasitology 160 $76-82$.

Simeonov, A., Jadhav, A., Sayed, A. A., Wang, Y., Nelson, M. E., Thomas, C. J., Inglese, J., Williams, D. L. and Austin, C. P. (2008). Quantitative high-throughput screen identifies inhibitors of the Schistosoma mansoni redox cascade. PLoS Neglected Tropical Diseases 2, e127.

Sithiathaworn, P., Sripa, B., Kaewkes, S. and Haswell-Elkins, M. (2009). Food-borne trematodes. In Manson's Tropical Diseases 22nd Edition (ed. G. C. Cook and A. I. Zumla ). Saunders, London, pp. 1461-1476.

Smithers, S. R. and Terry, R. J. (1965). The infection of laboratory hosts with cercariae of Schistosoma mansoni and the recovery of the adult worms. Parasitology 55, 695-700.

Smyth, J. D. and Halton, D. W. (1983). The Physiology of Trematodes. Cambridge University Press, Cambridge.

Steinmann, P., Keiser, J., Bos, R., Tanner, M. and Utzinger, J. (2006). Schistosomiasis and water resources development: systematic review, meta-analysis, and estimates of people at risk. Lancet Infectious Diseases 6, 411-425.

Terasaki, K., Noda, Y., Shibahara, T., Itagaki, T., Fukuda, K. and Tsuchiya, K. (2003). Experimental fascioliasis in the rat-like hamster, Tscherskia triton, and other rodent hosts. Parasitology International 52, 147-154.

Toledo, R. and Fried, B. (2005). Echinostomes as experimental models for interactions between adult parasites and vertebrate hosts. Trends in Parasitology 21, 251-254.

Utzinger, J. and Keiser, J. (2004). Schistosomiasis and soil-transmitted helminthiasis : common drugs for treatment and control. Expert Opinion on Pharmacotherapy 5, 263-285.

Utzinger, J., Xiao, S. H., Tanner, M. and Keiser, J. (2007). Artemisinins for schistosomiasis and beyond. Current Opinion in Investigational Drugs 8, 105-116.

van der Werf, M. J., de Vlas, S. J., Brooker, S., Looman, C. W. N., Nagelkerke, N. J. D., Habbema, J. D. F. and Engels, D. (2003). Quantification of clinical morbidity associated with schistosome infection in sub-Saharan Africa. Acta Tropica 86, 125-139.

Vera-Montenegro, Y., Ibarra-Velarde, F., RamirezAvila, G. and Munguia-Xochihua, J. (2008). In vitro fasciolicide activity of some plant extracts against newly excysted flukes. Annals New York Academy of Sciences 1149, 180-182.

Webbe, G., James, C., Nelson, G. S. and Sturrock, R. F. (1981). The effect of praziquantel on Schistosoma haematobium, $S$. japonicum and $S$. mansoni in primates. Arzneimittel-Forschung 31, 542-544.

White, N. J. (2008). Qinghaosu (artemisinin): the price of success. Science 320, 330-334.

Xiao, S. H., Chollet, J., Booth, M., Weiss, N. A. and Tanner, M. (1999). Therapeutic effect of praziquantel enantiomers in mice infected with Schistosoma mansoni. Transactions of the Royal Society of Tropical Medicine and Hygiene 93, 324-325. 
Xiao, S. H., Keiser, J., Chollet, J., Utzinger, J., Dong, Y., Vennerstrom, J. L. and Tanner, M. (2007). The in vitro and in vivo activities of synthetic trioxolanes on major human schistosome species. Antimicrobial Agents and Chemotherapy 51, 1440-1445.
Yolles, T. K., Yolles T. K., Moore D. V., De Giusti D. L., Ripsom C. A., Meleney H. E. (1947). A technique for the perfusion of laboratory animals for the recovery of schistosomes. Fournal of Parasitology 33, 419-426. 